\title{
Giacomo Pala
}

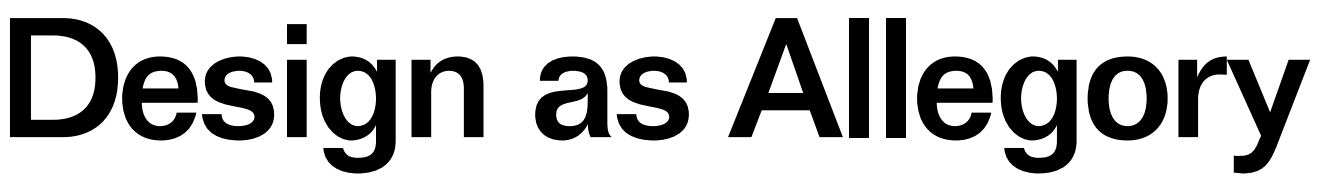

magine being alone, immersed in a peculiar reality - what some like to label 'digital': a virtual, confusing, but suggestive world you have built by using the most advanced technologies at your disposal. You are seemingly alone and connected with thousands of people, but they are no less alone than you are. Details aren't fully understandable, but you grasp that something is going on. We all feel the same. We are all parodically moving in a labyrinth of traces, signs and symbolsmoving as we are in an immersive maze of realities. We all chose the traces to follow, the signs to read and the symbols to interpret, and we contribute to their making. We simultaneously create and sort information, ideas and forms. Like geographers of an unknown world, we all produce maps helping us to make sense of the strange environment we experience. We generate, in this way, diverse narratives: varied perceptions and parallel realities, which themselves also multiply, meet and diverge. If we had to give a name to who we are, that would be what Walter Benjamin has defined as allegorists: people "for whom objects represent only keywords in a secret dictionary," since "the allegorist can never have enough of things." And we can't stop looking at newer and newer things, immersed as we are in the midst of different perceptions of reality. We can only make it our own by endlessly selecting things in order to create possible meanings. But allow me to ask a possibly silly question: what if the 'digital'-whatever it is - would allow us to simultaneously sort and combine all the possible meanings? It would be an incredibly complex world in which different perceptions and ideas would come together, not without any conflict. Identity and difference would lose their antinomic relationship, producing possibly contradictory and fragmentary realities, but all the more interesting precisely for this reason.

But let's assume something different. Imagine: what if the practice of designing was the possibility of composing preexisting and different realities, engaging the world by producing new meanings? Design - the act of generating something by composing its parts-would become the practice of constantly altering and reorganising available narratives and data in order to make something of them. The plurality and heterogeneity of preexisting stories and perceptions - with their forms, products and structureswould become the starting point of such a practice. To design would also mean to leave behind the idea of creating new 


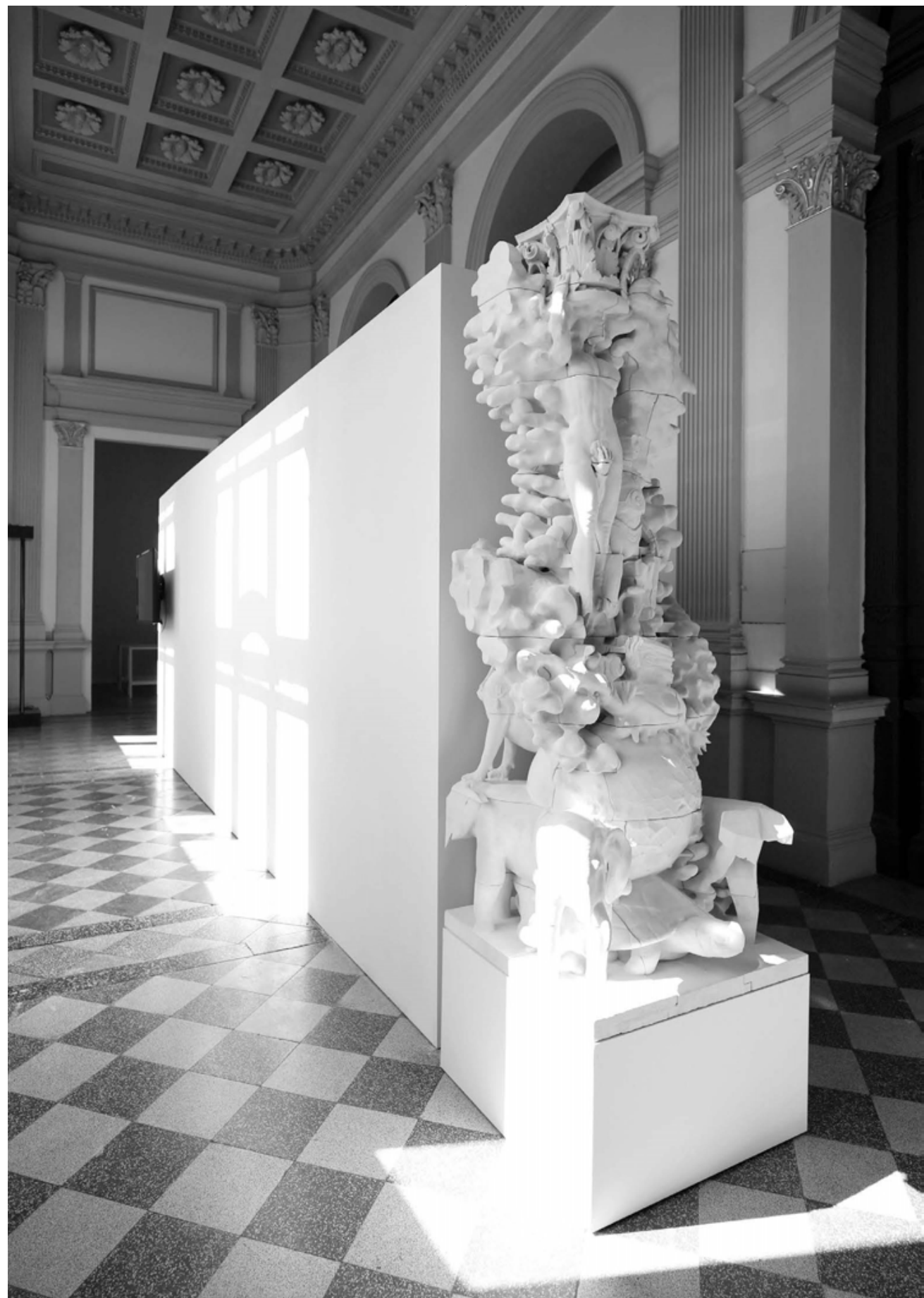

Fig. 1 A sculpture designed by Giacomo Pala and Stefan Maier, in collaboration with David Kienpointner as part of the installation Hypnerotomachia Naturae, designed and curated by Bart Lootsma and the team of Architekturtheorie at the Landes-Museum in Innsbruck, Austria. 
autonomous originals. It would rather testify to a disposition to insert its products in a world of pre-existing signs, significations, narratives and symbols. This kind of activity would also imply the endless exploration of different realities, as well as the re-writing of historical narratives and the endless construction of canons. If so, to design wouldn't any longer be a matter of filling a blank page with ideas and intuitions, or 'creating' something estranging on the basis of some sort of teleological virginity. It would be a matter of finding procedures and ways of putting things together in order to critically produce meanings. This kind of practice would be involved in a constant seizing of cultural codes, discourses and mundane notions. The main objective of a designer would be one of composing, or even re-composing objects, creating a democracy of meaning(s).

All possible realities, times and ideas would occur at the same time, and each would also be the point of departure for new possibilities, for new compositions and assemblages of differences. The designer would activate different selected histories, myths and narratives, recreating them by copying and pasting together its images and forms and by placing pre-existing notions one next to the other. To design would also mean to be engaged in the imagination of the links between differences: to think about possible ways through which different things, entities and ideas may be related to one another. Then, a designed object would be something like a riddle, or rather, an allegory: "a rebus-writing composed of concrete images." It wouldn't just be the practice of creating objects and space. Design would involve the re-creation of meanings. Designers, architects, or artists could travel between parallel realities, bringing together different perceptions, defining meanings by manipulating geometry and form. The results of the design process would be incomplete, but not untrue, re-presentations of the world we live inbe it digital, or analogue. In contrast to simplistic and mechanistic notions of history, culture and knowledge, this kind of allegorical design would not be the expression of an absolute actuality, or of a single dogma. Series of timepieces would come together, bridging their fractures. Design would be the outcome of a practice allowing the composition of wholes made of divergent, convergent and parallel notions. Design wouldn't be the simple representation of a truth, it would rather transform it in a hybrid, reinventing it. Ultimately, what I have asked you to imagine until now is a design strategy enabling us - all of us - to reinvent and recreate meanings for our world and, through its aesthetics, acquire cultural and political content. It is the attempt of thinking about design as one of the means allowing the activation of the forms, cultural objects and narratives of our daily lives, transforming them into something new. It is a way of transcending the banality of common sense thanks to juxtapositions, combinations and re-compositions. Ultimately, to think in such a way about design - the creation of allegorical, alternative, but immanent, realities - is to imagine possible ways of making sense of the strange world we have ended up living in; to understand how to make it our own and how to actively dwell in it.

1 Walter Benjamin (translated by Howard Eiland and Kevin McLaughlin), The Arcades Project, (Cambridge: Harvard University Press, 1999), p. 211

2 Craig Owens, Beyond Recognition: Representation, Power and Culture, (Berkley: University of California Press, 1992), p. 57 